\title{
MERCANTILIZAÇÃO DA FORMAÇÃO DE PEDAGOGOS NO BRASIL
}

\author{
Sandra Cristina Vanzuita da Silva ${ }^{1}$ \\ Valéria Silva Ferreira²
}

\section{RESUMO}

Este trabalho evidencia fatores que permitem a inserção de redes privadas na oferta do curso de Pedagogia. Os dados produzidos a partir de documentos do governo, IES pesquisadas e empresas de consultoria apontam que o curso tem se tornado um mercado lucrativo, ofertado por uma rede que envolve instituições, pessoas, políticas e interesses comerciais. A pesquisa questiona como a formação inicial tem contribuído para o desenvolvimento profissional dos Pedagogos, responsáveis pela educação básica, pela coordenação e gestão das escolas em todo Brasil.

Palavras-chave: Pedagogia. Privatização. Mercantilização.

\section{MERCANTILIZATION OF THE FORMATION OF PEDAGOGUES IN BRAZIL}

\section{ABSTRACT}

This work highlights factors that allow the insertion of private networks in the offer of the Pedagogy course. The data produced from government documents, researched HEls, and consulting firms point out that the course has become a lucrative market, offered by a network that involves institutions, people, policies and commercial interests. The research questions how the initial formation has contributed to the professional development of Pedagogues, responsible for basic education, coordination and management of schools throughout Brazil.

Keywords: Pedagogy. Privatization. Mercantilization.

\section{MERCANTILIZACIÓN DE LA FORMACIÓN DE PEDAGOGOS EN BRASIL}

\section{RESUMEN}

Este trabajo evidencia los factores que permiten la inserción de las redes privadas en la oferta de cursos de graduación de enseñanza superior en Pedagogía. Los

1 Doutora em Educação. Universidade do Vale do Itajaí - UNIVALI - Itajaí/SC/Brasil Professora do PPGE - Programa de Pós-Graduação em Educação da Universidade do Vale do Itajaí - UNIVALI - Orcid iD: 0000-0001-5853-9592. E-mail: sandras@univali.br

2 Doutora em Educação. Universidade do Vale do Itajaí - UNIVALI - Itajaí/SC/Brasil Professora do PPGE - Programa de Pós-Graduação em Educação da Universidade do Vale do Itajaí - UNIVALI - Orcid iD: 0000-0002-3990-7182. E-mail: v.ferreira@univali.br 
datos producidos a partir de los documentos del gobierno, IES (Instituciones de Enseñanzas Superiores) y empresas de consultoría señalan que este curso se ha convertido en un lucrativo mercado, ofrecido por una red que involucra las instituciones, las personas, los políticos e intereses comerciales. Así, la investigación cuestiona como ésta formación contribuye al desarrollo profesional de los Pedagogos, responsables por la enseñanza básica, por la coordinación y por la gestión de las escuelas en todo Brasil.

Palabras clave: Pedagogía. Infraestructura. Mercantilización.

\section{INTRODUÇÃO}

Com o surgimento da modernidade, a Educação ocupa na sociedade um status privilegiado. Adorno (1995) afirmava que seria por meio da educação que o sujeito poderia emancipar-se e desenvolver sua autonomia, libertar-se e equipar-se para se orientar no mundo. Esse é um discurso incorporado pela maioria e poucos o têm contestado, pois políticas educacionais e outros aparatos governamentais são criados para que os sujeitos passem a maior parte do tempo de sua vida dentro de uma escola. Para Saviani (2007), esses dispositivos legais são criados principalmente com o objetivo de amenizar os desastrosos efeitos sociais causados pelas políticas econômicas que, segundo o autor, mais favorecem os interesses privados do que melhoram a condição de vida das populações menos favorecidas.

As discussões acerca dos serviços educacionais prestados pelo Estado ou por instituições privadas apontam uma relação desta oferta com a qualidade (CAMPOS; FÜLLGRAF; WIGGERS, 2006; DOURADO, 2007; CURY, 2010). E, pensar em uma Educação de qualidade remete-nos a muitas questões, entretanto duas são fundamentais: Quem é o sujeito que ensina na escola? E o que ele ensina? A resposta sempre aponta o professor, licenciado nas diferentes áreas ou o bacharel em Pedagogia. Embora tenhamos a compreensão de que há outros atores presentes nos espaços escolares que também eduquem, é o professor a peça chave no ensino. Além disso, os Pedagogos são os profissionais responsáveis pela educação das crianças, tanto na Educação Infantil, quanto nos Anos Iniciais do Ensino Fundamental, por ministrar aulas no Normal Médio e formar outros 
professores. Atuam também, em muitos sistemas de ensino, como coordenadores pedagógicos e gestores de unidades escolares.

Neste sentido, o presente artigo pretende evidenciar os fatores que permitem a inserção de redes privadas na formação inicial de Pedagogos no Brasil e, discutir as implicações do modelo ofertado para sua atuação profissional na educação básica. É resultado de uma tese de doutorado, que tem como discussão central a formação inicial de Pedagogos que, no Brasil, tem sido desenvolvida prioritariamente por instituições privadas, em uma perspectiva mercantilista.

Ressaltamos que os dados analisados são todos públicos e foram encontrados nos sites oficiais das empresas de consultoria, dos organismos internacionais, dos setores públicos e das instituições de Ensino Superior analisadas. Dessa forma, os preceitos éticos de proteção aos sujeitos foram respeitados.

Utilizamos como fundamento para a análise dos elementos encontrados na coleta de dados os trabalhos desenvolvidos por autores da Sociologia Crítica como Ball (2007), pois, para Apple (2013), dentre os autores que se dedicam a desenvolver um trabalho crítico sobre as formas de inserção do setor privado na educação, poucos são tão bons como Stephen Ball. Concordamos com Apple (2013), pois Ball nos faz refletir de forma profunda sobre como as políticas, as reformas e as inovações são racionalizadas e utilizadas para (re)organizar o Estado e trazer as normas do privado para o público com agilidade e de forma eficaz.

Mainardes e Stremel (2011) apontam que as ideias desenvolvidas por Ball não pretendem explicar as políticas, as reformas ou as ações do Estado, mas sim sugerir uma maneira de pesquisar e teorizar essas ações, rejeitando a ideia de que elas são apenas implementadas. Para os autores, Ball pode estimular o pesquisador a assumir compromissos éticos com os temas investigados. Essa contribuição está relacionada com as discussões sobre "[...] reflexividade ética e importância de se fazer uma auditoria ética do impacto e resultado das políticas e dos princípios e finalidades da pesquisa qualitativa crítica" (MAINARDES, 2013, p. 5). 
Além disso, os estudos de Stephen Ball poderão ajudar-nos a compreender qual o papel do setor privado na formação inicial dos Pedagogos, que reflexos esse modelo irá trazer para a Educação. Ball (2007) alega que as incursões de privatização sobre o setor público educacional estão insustentáveis, mas, infelizmente, não há volta. O que podemos fazer então, de acordo com o autor, é analisar criticamente as mudanças, em suas tecnologias, regimes e estratégias, o que pode fornecer-nos condições de olhar para os impactos éticos e democráticos sobre a formação inicial dos Pedagogos.

Gatti, Barretto e André (2011), nos mostram a importância deste trabalho quando afirmam que, um dos principais aspectos a considerar, quando se pensa em pesquisas sobre a formação de Pedagogos é a formação inicial. Porque, segundo as autoras, na constituição da docência, esse é o primeiro ponto de acesso ao desenvolvimento profissional contínuo cujo papel é fundamental na qualidade dos docentes. Vaillant (2006) corrobora com estas preocupações quando apresenta algumas inquietações no que diz respeito à formação inicial de Pedagogos, como; a heterogeneidade e a diversidade das instituições formativas.

As pesquisas citadas anteriormente apontam duas questões fundamentais para o tema deste trabalho. A primeira diz respeito às pressões que o setor educacional tem sofrido, advindas de variados grupos sociais, dos novos ordenamentos estruturais do mundo contemporâneo e das novas competências exigidas para o desenvolvimento da prática docente. A segunda, com relação às decisões do governo em relação às políticas para a educação, pois elas definem a importância atribuída ao setor educacional. Gatti, Barretto e André (2011) ainda sinalizam que a forma como são estabelecidas e como tais políticas são postas em ação - sua articulação, ou não, entre si e com políticas mais amplas, o seu financiamento e gerenciamento -, "[...] oferece indícios da sua adequação e informa sobre o tipo de impacto que poderão ter no desenvolvimento de outras ações e programas governamentais" (GATTI; BARRETTO; ANDRÉ, 2011, p. 13). 
Brejo (2012) desenvolveu em sua tese, um estudo comparativo das políticas nacionais de formação de professores da Educação Infantil no Brasil e na Argentina entre os anos de 1990 e 2010. Em suas análises, a autora revela que nos dois contextos há um aumento significativo na criação de políticas educacionais desde a década de 1990. E, uma forte tendência, direta ou indireta, na indicação da qualidade do ensino estar relacionada somente à formação inicial dos Pedagogos, reduzindo outras dimensões igualmente preponderantes.

No Brasil de forma explícita, vemos o impacto da política de formação de professores, se revelar nos dados apresentados pelo Censo do Ensino Superior, publicado pelo Instituto Nacional de Estudos e Pesquisas Educacionais Anísio Teixeira (BRASIL, 2018). Segundo o documento, os cursos em Educação têm crescido muito nas últimas décadas. As áreas de Ciências Sociais, Negócios e Direito, seguida da Educação, são as áreas que apresentam um maior número de instituições. Esses são os cursos que mais cresceram, pois demandam de pouco investimento das instituições privadas em laboratórios ou materiais específicos para a formação dos profissionais. São cursos que podem ser ofertados no período noturno, o que dá a oportunidade ao estudante de trabalhar para pagar sua mensalidade.

Segundo Gatti, Barretto e André (2011), as instituições públicas pouco ofereceram, na última década, cursos de bacharelado com licenciatura a distância. Nesse tipo de curso e modalidade de ensino, as matrículas ocorrem muito mais na área privada e com um aumento bem significativo. Para a autora, a inversão nesses dados está certamente associada a políticas que favorecem esse segmento de Instituições de Ensino Superior (IES). Diante de tal realidade, reafirmamos que a formação dos Pedagogos no Brasil tem se tornado um mercado lucrativo, pois, como podemos observar, a formação tem sido feita fora das universidades públicas, longe da pesquisa e de outros projetos que contribuem para sua qualidade.

Assim, ao refletirmos sobre a mercantilização da formação de Pedagogos no Brasil, discorreremos neste artigo, sobre como o neoliberalismo forma a base para os interesses capitalistas sobre a 
Educação, principalmente, no ensino superior e na oferta de cursos de Pedagogia. Trataremos sobre os entrelaçamentos $e$ os modos de cooperação na construção da rede entre organizações, políticas públicas e setor privado para a formação de Pedagogos. E, discutiremos quais os possíveis impactos para o projeto de Educação que se pretende no Brasil, tendo essa realidade como regra geral e não como exceção.

\section{O caminho que percorremos para entender 0 modelo mercantilista de formação inicial de Pedagogos no Brasil}

Algumas interrogações representam $\circ$ ponto de partida para empreendermos este estudo aqui apresentado, dentre elas: Como as políticas públicas são utilizadas para promover a entrada das redes privadas na formação de Pedagogos no Brasil? Como organismos internacionais, setor público e privado constituem uma rede de interesses para a inserção de instituições privadas na formação de Pedagogos?

Para chegarmos a algumas respostas, percorremos um caminho metodológico que teve como referência a abordagem qualitativa, pois Ball (2013a) afirma que, para lidar com um fenômeno tão complexo como as questões ligadas à parceria público-privada, um novo grupo de conceitos e métodos é necessário. O autor afirma que as contínuas mudanças em governança educacional dentro de uma estrutura global, em que vários organismos e instituições influenciam as decisões de governos, mudam com muita rapidez as estruturas educacionais, ou seja, o que ocorre hoje, amanhã poderá se transformar.

Considerando as ponderações do autor nesta pesquisa, coletamos e analisamos dados em diferentes fontes. Documentos oficiais do governo, sites dos maiores conglomerados educacionais que atuam no Brasil, redes de consultoria privadas, sindicatos e instituições não governamentais, especializadas em educação. Segundo Sá-Silva, Almeida e Guindani (2009), o uso de documentos em pesquisa deve ser apreciado e valorizado. A riqueza de informações que deles pudemos extrair e resgatar justifica o seu uso porque "[...] possibilita ampliar o entendimento de objetos cuja 
compreensão necessita de contextualização histórica e sociocultural" (SÁSILVA; ALMEIDA; GUINDANI, 2009, p. 2).

Nesse sentido, o primeiro passo no desenvolvimento deste estudo foi a análise dos documentos que apresentaram dados estatísticos, principalmente, o Censo do Ensino Superior (BRASIL, 2018), os Relatórios produzidos pelo Sindicato das Entidades Mantenedoras de Estabelecimentos de Ensino Superior no Estado de São Paulo (SEMESP) e relatórios das empresas de consultorias como a CM Consultoria. Nesta etapa da pesquisa, encontramos o número de matrículas dos cursos de Pedagogia e em que regiões esses números eram mais expressivos, o que nos deu a possibilidade de confirmamos que a oferta do curso de Pedagogia era feita prioritariamente por instituições privadas.

Nossa próxima preocupação residia, então, em compreender porque esse fenômeno crescia com tal expressividade no país. Para tanto, analisamos as políticas públicas direcionadas à formação inicial de Pedagogos, principalmente, a Lei de Diretrizes e Bases Nacionais (LDB 9394/96) e as Diretrizes Curriculares Nacionais para os cursos de Pedagogia.

Para compreendermos a evolução do fenômeno e quais elementos e instituições influenciaram o crescimento da oferta de cursos de Pedagogia, selecionamos três documentos que pudessem representar as três últimas décadas, construídos por diferentes organizações. Assim analisamos:

1. O Plano Decenal de Educação para Todos (BRASIL, 1993).

2. O Documento Educação para Todos: avaliação da década (BRASIL, 2000).

3. E dois documentos produzidos pelo movimento Todos Pela Educação em 2011 e 2014.

As informações foram coletadas na internet, obtidas nos sites das instituições pesquisadas. Segundo Ball (2014), a internet oferece um vasto potencial de materiais relevantes, que podem ser obtidos em websites governamentais e de empresas, assim como em blogs, serviços de vídeo, relatórios de reuniões, postados em páginas da web. Corroborando com a perspectiva de Ball (2013b), Shiroma (2014) propõe que a internet pode 
revelar a rede de relações e as conexões entre Estado, sociedade civil e organizações multilaterais. Pode revelar também, segundo a autora, suas ações, seus discursos, suas motivações e os recursos utilizados para o estabelecimento de novos papéis e relações políticas, garantindo os interesses de uma elite hegemônica, conectados cada vez mais pelos mais variados interesses econômicos e sociais.

Assim, o conjunto de materiais reunidos neste trabalho interpretativo pretende mostrar uma rede representada por vozes, imagens, documentos entre outros materiais que permitem observar a sequência de ligações entre setor público, movimentos, órgão supranacionais, organizações não governamentais, entre outros atores interessados no negócio da formação de Pedagogos.

Ressaltamos que os dados analisados são todos públicos e foram encontrados nos sites oficiais das empresas de consultoria, dos organismos internacionais, dos setores públicos e das instituições de Ensino Superior analisadas. Dessa forma, os preceitos éticos de proteção aos sujeitos foram respeitados.

É importante lembrar que, como toda pesquisa, esta também apresenta seus limites de tempo, das escolhas teóricas e das escolhas dos dados. Contudo, nosso desejo é que, a partir das reflexões aqui propostas, outros estudos se atrevam a encontrar relatos, evidências e dados que possibilitem o confronto com as ideias aqui reveladas, produzindo, assim, novos conhecimentos e posicionamentos críticos que possam contribuir para o campo da formação inicial de Pedagogos.

\section{Contexto local: a privatização do ensino superior no Brasil e suas ligações com oferta de formação de Pedagogos}

No contexto mundial, o fenômeno de privatização da educação pública tem ocorrido sob diferentes configurações. Essa é uma evidência trazida por pesquisas produzidas no Brasil (HADDAD; GRACIANO, 2004; OLIVEIRA, 2009; ADRIÃO, 2009; SAMPAIO, 2010 2011a, 2011b; PERONI, 2013; CARVALHO, 2015; MANCEBO; VALE, 2015) e em outros países do mundo 
(DALE, 1994, 2011; ROBERTSON, 2015; BALL, 2007, 2013b, 2014; VERGER, 2011, 2014; KLEES; EDWARS JR., 2015). Segundo os estudos, esses modelos podem ser desde o fornecimento de materiais ou os chamados kits pedagógicos, até a oferta de vagas para os diferentes níveis de ensino. Porém, muito mais do que uma constatação, as referidas pesquisas alertam para uma questão importante: esse é um movimento camuflado com palavras de ordem neoliberal - inovação, reforma e modernização dos sistemas públicos.

Para enfrentar esse desafio, Carvalho (2015) afirma que, ao longo dos últimos dez anos, as políticas públicas educacionais nos países desenvolvidos e em desenvolvimento têm privilegiado um modelo velado de privatização, por meio das parcerias público-privadas. Segundo a autora, esse fenômeno ocorre principalmente no Ensino Superior, campo de qualificação de mão de obra para o mercado.

No Brasil, essa é uma estratégia que tem apresentado como resultado, única e exclusivamente, o aumento da oferta de vagas, principalmente, em instituições privadas. No campo da formação de Pedagogos, o que se observa é a mesma estratégia: instituições privadas que têm formado mão de obra tanto para as escolas públicas quanto para as privadas. Em maior número para instituições públicas, pois o campo da Educação Infantil tem crescido significativamente.

As instituições de ensino superior privadas perceberam esse nicho de mercado e começaram a promover cursos emergenciais, ofertados nos finais de semana e nos períodos das férias escolares. Outro modelo que também surge são os cursos da Educação a Distância (EAD). Ball (2010) afirma que a expansão rápida do setor privado sobre a educação pública, não só a área educacional, no sentido de prestação de serviço, mas também de influência de definição de currículo, propostas metodológicas e formação dos profissionais da educação. A formação de Pedagogos é então, impulsionada pelos dois lados da relação de troca, oferta e demanda. O autor chama metaforicamente essa situação de "currículo neoliberal da reforma do setor público" (BALL, 2010, p. 21). Nesse sentido, criar a demanda é sempre muito importante. Fazer reserva de mercado é 
ainda outra estratégia capitalista, o papel do mercado é procurar as necessidades do Estado, ou seja, "[...] só podemos entender a disseminação do formato de mercado em relação ao papel do Estado como criador do mercado, e o papel do mercado em relação às necessidades políticas e econômicas do Estado" (BALL, 2010, p. 23).

Em entrevista ao Portal regional.com.br (2013), o presidente da CM Consultoria declara que a educação privada é, sem dúvida, um bom negócio no Brasil. Para o presidente, as instituições de ensino, mesmo desorganizadas administrativamente, ainda são um bom negócio. "Agora, aquelas que têm um bom sistema de gestão, que estão bem estruturadas, são extremamente rentáveis sim. E eu não vejo nada de pejorativo nisso", afirma o presidente, que ainda defende a ideia de que essas instituições tem um objetivo maior a perseguir, que é o lucro e, para terem lucro, têm de oferecer um serviço que atenda às expectativas de seus clientes. Para Monteiro (2013):

Este processo de consolidação do ensino superior privado tem promovido uma reviravolta, sofrendo várias alterações. A tendência é que, embora em menor volume e velocidade, as fusões, aquisições e a formação de redes educacionais continuem a dar o tom ao já concorrido mercado do ensino superior privado brasileiro (CM CONSULTORIA, 2013).

Esses dados revelam que a formação de Pedagogos no Brasil é feita por empresas que se preocupam exclusivamente com o lucro e consideram o futuro professor da Educação Básica como uma mercadoria. Nesse sentido, surgem alguns questionamentos: Que projeto de Educação temos para o Brasil? Onde está o compromisso com a construção de uma Educação justa e igualitária?

Entendemos que as políticas produzidas para a formação de professores e, por consequência, a formação de Pedagogos são influenciadas por diferentes atores e contextos e acabam por colaborar, mesmo que de forma velada, com a oferta dos cursos pelo setor privadomercantil. 
Ball (2013a) afirma que, para lidar com um fenômeno tão complexo como as questões ligadas à parceria público-privada, um novo grupo de conceitos e métodos é necessário. O autor afirma que as contínuas mudanças em governança educacional dentro de uma estrutura global, onde vários organismos e instituições influenciam as decisões de governos, mudam com muita rapidez as estruturas educacionais, ou seja, o que ocorre hoje amanhã poderá se transformar. Segundo o autor, a educação está cada vez mais sujeita aos processos de mercantilização e privatização. Essas são algumas das principais características da política de educação global no século XXI e, para lidar com esta complexidade, Ball (2013a) afirma que devemos explorar como e por quem a governança educacional está sendo realizada.

Entrelaçamentos e modos de cooperação na construção da rede entre organizações, políticas públicas e setor privado para a formação de Pedagogos

Olhar o fenômeno de mercantilização e centralização do poder sobre a Educação, que estamos vivendo na atualidade, de forma mais atenta, faz-se necessário, pois as ideias do neoliberalismo têm sustentado a produção dos entrelaçamentos, ou conexões entre a rede de interesses capitalistas e as organizações institucionais, por meio das mais variadas formas de conexão.

Dessa forma, as ideias neoliberais são expressas, como o eixo condutor do processo de mercantilização do Ensino Superior e, consequentemente, da formação de Pedagogos. De acordo com Burles e Torres:

\begin{abstract}
Em termos educacionais, existe uma compreensão crescente de que a versão neoliberal da globalização, particularmente da forma implementada (e ideologicamente defendida) por organizações bilaterais, multilaterais e internacionais, reflete-se em uma agenda educacional que privilegia, se não impõe de modo direto, certas políticas de avaliação, financiamento, padrões, formação de professores, currículo, instrução e testes (BURLES; TORRES, 2004, p.19).
\end{abstract}

No que tange à formação inicial de Pedagogos, podemos destacar que, nas últimas décadas, tempos de reorganização da economia mundial, 
aqui também no Brasil o cenário educacional foi fortemente influenciado pela construção e promulgação da Lei de Diretrizes e Bases 9.394/96, uma política que fortaleceu o crescimento das IES privadas no Brasil, impactando também a formação de professores.

A referida lei exige que todos os professores da Educação Básica se formem em nível superior, o que de certa forma qualificaria a ação docente. Entretanto, é preciso um olhar mais atento, pois a lei também considera a possibilidade da formação desses profissionais ser promovida fora das universidades, distante da pesquisa e extensão. Diante de tal realidade, o ensino superior e, consequentemente a formação de Pedagogos, tornava-se mais uma prestação de serviços, executada por redes privadas sob o controle do Estado.

As palavras de ordem são globalização, Estado mínimo, sociedade do conhecimento, qualidade total, empregabilidade, etc. e, o contexto educacional é o melhor espaço para a introdução e disseminação desse conhecimento. Um Brasil moderno necessitaria de professores e Pedagogos, qualificados, reciclados, formados no Ensino Superior. Como o governo não tem uma política forte de formação de professores e nem espaço em instituições públicas para que isso aconteça, o mercado opera suas tecnologias e, por meio de soluções rápidas e baratas, supri a necessidade da sociedade.

Nossa sociedade é uma sociedade de consumo, assim afirmava Bauman (1999). Porém, quando falamos de uma sociedade de consumo é preciso acrescentar algo mais a esta afirmação clichê: "[...] todos os membros dessa sociedade consomem; todos os seres humanos, ou melhor, todas as criaturas vivas 'consomem' desde tempos imemoriais" (BAUMAN, 1999, p. 87, grifo do autor). Para o autor, passamos pela modernidade, em sua fase meramente industrial, de uma "sociedade de produtores" para uma "sociedade de consumo".

$\mathrm{Na}$ contemporaneidade, segundo o autor, todo mundo pode ser lançado na moda do consumo; pode desejar ser um consumidor e aproveitar as oportunidades que esse modo de vida oferece. Contudo, 
Bauman adverte: nem todo mundo pode ser um consumidor - para tornar o desejo de consumo realmente desejável e assim extrair prazer do desejo, deve-se ter uma esperança racional de chegar mais perto do objeto desejado. Assim, "[...] essa esperança, racionalmente alimentada por alguns, é fútil para muitos outros. Todos nós estamos condenados à vida de opções, mas nem todos temos os meios de ser optantes" (BAUMAN, 1999, p. 94).

Contudo, o consumo não se traduz apenas naquilo que é material somos consumidores também de conhecimento. Ter o Ensino Superior significa também uma possibilidade de ascensão social. Mas, quais cursos podem ser baratos e acessíveis à camada da população que não tem oportunidade tanto financeira quanto intelectual? Cursos à distância e formação de professores.

De acordo com Brown e Lauder (2013), a educação deve ser entendida como um local de lutas entre grupos e não apenas como desenvolvimento econômico e justiça social e não como um comércio de produtos baratos à exposição. A complexidade desse campo deve ser vista de forma multifacetada e analisada a partir das desigualdades na educação em relação à classe social, ao patriarcado e às estruturas racistas e, ainda, às políticas criadas pelo Estado. Diante de tal afirmação, perguntamo-nos: Estamos formando Pedagogos para atuação nesse campo dos conflitos educacionais? As instituições privadas, na sua grande maioria faculdades de centros universitários ou apenas polos de encontros presenciais, têm dado oportunidade aos Pedagogos e condições materiais para que esse sujeito enfrente e supere as desigualdades sociais, garantindo às nossas crianças o ensino sistematizado? É necessário que pensemos não só em aumentar a oferta, mas no que realmente estão aprendendo esses profissionais nessas instituições.

O envolvimento dos organismos internacionais e regionais, postos a serviço do capital e vinculados aos mecanismos de mercado, está encarregado de produzir pesquisas e avalição para a área educacional (BALL, 2012, 2013) que legitimam esta realidade. De forma bem sistemática, o Fundo Monetário Internacional (FMI), O Banco Mundial (BIRD), O Banco 
Interamericano de Desenvolvimento (BID) e o Programa das Nações Unidas para o Desenvolvimento (PNUD), e muitos outros, têm monitorado os resultados, tanto das reformas quanto da implementação de políticas educacionais nos países do capitalismo periférico e semiperiférico, como, por exemplo, nos países Latino Americanos e do Caribe, na Ásia, na África Subsariana, na Arábia Saudita, dentre outros (FRIGOTTO; CIAVATTA, 2003). Relatórios, dados, tratados, geram uma série de recomendações que legitimam a criação de políticas, mas, acima de tudo, imprimem um respaldo legal que permite ações muitas vezes arbitrárias.

Na maioria dos documentos, o destaque é dado para o papel preponderante do professor, tanto na qualidade quanto no sucesso nos meios educacionais. Um exemplo disso é relatado por Frigotto e Ciavatta (2003, p. 96): "[...] no plano jurídico-econômico, a Organização Mundial do Comércio $(\mathrm{OMC})$ vai tecendo uma legislação cujo poder transcende o domínio das megacorporações e empresas transnacionais". Os autores afirmam, também, que, para o capital, é interessante ter presente o papel da OMC, pois em uma de suas últimas reuniões, a organização apresentou dados afirmando que um dos espaços mais fecundos para negócios rentáveis era o campo educacional.

Oliveira (2008) reforça que, na área da Educação, a participação das agências e organismos internacionais tem sido decisiva para o fortalecimento da descentralização dos serviços públicos federais para as esferas municipais de governo. Por meio de estudos e relatórios que apontam diagnósticos negativos e receituários para a melhoria da educação e do trabalho dos professores, estão o Banco Mundial (BM), Banco Interamericano para a Reconstrução e o Desenvolvimento (BIRD), Programa das Nações Unidas para a Educação, Ciência e Cultura (UNESCO), Organização para a Cooperação e Desenvolvimento Econômico (OCDE), Fundo das Nações Unidas para a Infância (UNICEF), Programa das Nações Unidas para o Desenvolvimento (PNUD) e, na América Latina, principalmente, a Associação de Educadores da América Latina e do Caribe (AELAC). Essas entidades têm prestado valiosas contribuições, ao 
mesmo tempo em que induzem as políticas educacionais dos países em desenvolvimento, que, para cumprir tratados e acordos internacionais, se veem a mercê de tecnologias criadas por empresas privadas para melhorar sua performance, ou melhorar seus resultados.

Sobre essa questão, Ribeiro (2006) destaca que o setor educacional, em todos os níveis, está inserido como um dos setores de serviços negociáveis dentro do Acordo Geral sobre Comércio de Serviços (GATS), um dos pilares jurídicos da OMC. Ribeiro (2006) ainda indica que ocorreram várias especulações sobre como os doze (12) setores de serviço que fazem parte da lista do GATS foram escolhidos. No caso da educação, a pressão para inclusão na lista era por parte dos países desenvolvidos interessados no potencial lucrativo do mercado de serviços educacionais. O lobby veio, principalmente, dos Estados Unidos, da Austrália e da Nova Zelândia, países que, historicamente, recebem um grande número de estudantes internacionais e têm interesse em acessar os mercados internacionais de Educação para suas instituições.

Nesse sentido, o Estado tem se esforçado na criação de políticas públicas para o aumento do acesso a todos os níveis de Educação, mas, principalmente, as políticas para acesso ao Ensino Superior, que afetam, por consequência, a formação dos Pedagogos. São exemplos das ações produzidas pelos governos: o Sistema Nacional de Avaliação da Educação Superior (Sinaes), que cria rankings das universidades e atua como um regulador não tradicional da mesma forma que a mão invisível do mercado, do liberalismo clássico (BARREYRO, 2004); o Fundo de Financiamento Estudantil (Fies); e o Programa Universidade para Todos (Prouni), que tem como finalidade a concessão de bolsas de estudo integrais e parciais em cursos de graduação e sequenciais de formação específica, em instituições de Ensino Superior privadas.

Ball (2013a) sinaliza que, as políticas liberais buscam soluções apropriadas para mediar e possibilitar que as metas do Estado sejam alcançadas. Em consequência, público e privado fortalecem-se. O mercado garante seus clientes, o governo apresenta índices comprovando que os 
estudantes brasileiros e os professores tenham acesso ao Ensino Superior. Em suas pesquisas, vários autores (CARVALHO, 2013; SAMPAIO, 2010, 2011a, $2011 \mathrm{~b}$; SIQUEIRA, 2009; SGUISSARDI, 2008; OLIVEIRA, 2009) afirmam que a Educação transformou-se em uma mercadoria de grande valor. $E$, como podemos observar, um dos produtos mais atraentes é o dos cursos de Pedagogia.

Esse processo de crescimento desenfreado das instituições privadas de Ensino Superior faz-nos refletir sobre uma questão trazida por Paixão (2010), será que o avanço do capitalismo e a penetração do capital estrangeiro realmente seriam os únicos responsáveis pelos problemas no Ensino Superior, mas, especificamente, na formação de Pedagogos? Ou, seria também a falta de estratégias eficientes criadas pelos órgãos competentes, por meio de políticas públicas adequadas, visando controlar essas instituições?

\section{Fornecimento de soluçōes colaborativas do mercado de autoridades para a formação inicial de Pedagogos}

O programa "Todos pela Educação" é formado de partes interessadas em alavancar a Educação, por meio de comunidades de políticas geralmente baseadas em concepções compartilhadas de problemas sociais e suas soluções. Para que estas redes possam fornecer soluções colaborativas, elas mobilizam participações multifacetadas com os mais variados atores individuais ou grupos que tanto influenciam, patrocinam, ou, ainda, oferecem serviços e soluções.

No que diz respeito à formação de Pedagogos, é importante destacar que essas intenções traduzem-se em três pontos: formação, valorização e melhoria dos planos de carreira. Contudo, o que se vê na prática são políticas cada vez menos efetivas. Os discursos de valorização produzidos pela mídia traduzem a ideia da responsabilidade pelo ensino, ou seja, se as crianças não aprendem, a culpa é do professor que é mal formado e que ganha salários baixos. Porém, sabe-se que este não é o único condicionante para a qualidade do ensino e que, efetivamente, as políticas que dariam condições de melhoria pouco são citadas, como infraestrutura, um projeto

Revista Exitus, Santarém/PA, Vol. 9, № 5, p. 559 - 584, Edição Especial 2019. 
de formação inicial consistente e salários que realmente atraiam jovens para a carreira do magistério.

Para Sacristán (2002, p.24), "[...] o drama de educação é que ela não pode aproveitar as melhores pessoas que saem do sistema educativo para utilizá-las como reprodutoras da cultura no sistema educativo". O autor salienta que "[...] ninguém pode dar o que não tem". Isso significa dizer que se os professores não tiverem um nível de aprofundamento cultural satisfatório não podem produzir cultura. Conforme Sacristán (2002, p. 24): "Em primeiro lugar, se os professores não são bons profissionais, é preciso que sejam mais bem pagos, melhor considerados e recuperar características de sua profissionalidade".

Dos documentos produzidos pelo Todos pela Educação, Uma Agenda Urgente: Reflexões do Congresso Internacional, realizado pelo Todos Pela Educação em Brasília, em setembro de 2011, é o que tem apresentado propostas que incidem sobre a formação de professores e Pedagogos de forma mais explícita. O documento é o resultado das discussões produzidas nesse congresso internacional onde estavam presentes os mais variados atores interessados no campo educacional. O movimento produziu também outro documento onde estão descritas as Propostas para a Educação Básica no Brasil. O referido trabalho foi enviado na época aos candidatos à presidência do Brasil e reúne um conjunto de propostas para a Educação Básica brasileira, elaboradas por representantes de diferentes setores da sociedade brasileira convidados para inspirar os candidatos.

É interessante destacar que as propostas desses documentos trazem itens comuns que insistem em alguns temas centrais, desde o primeiro elaborado em 2011, até este último elaborado em 2014. Dentre esses temas estão: Prova Nacional, Formação continuada, Avaliação de desempenho dos professores e mudança nos currículos dos cursos de licenciatura e Pedagogia.

Se analisarmos os itens da proposta, podemos considerá-los despretensiosos e merecedores da atenção de pesquisadores e dos dirigentes responsáveis pela condução das políticas nacionais. Isso ocorre 
porque, segundo Ball (2014), nacionalmente, o setor educacional público está mais congestionado, novas formas de relacionamento são estabelecidas, ou seja, relações cada vez mais complexas. São as fronteiras entre o Estado, a economia e a sociedade civil, ficando cada vez mais turvas. "Há novas vozes nas conversas sobre políticas e novos canais por meio dos quais há uma proliferação, nacional e global, de redes políticas compostas de organizações operacionalmente autônomas, mas estruturalmente acopladas" (BALL, 2014, p. 34).

Uma série de organizações locais tem surgido na atualidade com o objetivo de prestar serviços a grandes conglomerados educacionais. Carvalho (2013) aponta algumas das principais empresas responsáveis pela coleta, análise e geração de dados para interessados em investir no mercado educacional:

\begin{abstract}
A pioneira no ramo é a CM Consultores, que atua desde 1988, cujo proprietário é o professor Carlos Antônio Monteiro, especializada em gestão educacional, na oferta de cursos e seminários. Destacam-se ainda: a PRS Consultores, Lobo \& Associados Consultoria e a Hoper Educacional. A primeira era de propriedade do ex-ministro da educação Paulo Renato de Souza, que parece estar desativada. A segunda está em funcionamento desde 1999 e é de propriedade de Roberto Leal Lobo e Silva Filho, ex-reitor e vice-reitor da Universidade de São Paulo (USP) e ex-reitor da Universidade de Mogi das Cruzes, que oferece assessoria, consultoria, além de ministrar cursos, seminários, workshops, treinamentos aos gestores das IES privadas e vender uma série de "produtos" direcionados a atender sua clientela. Seus sócios fundaram, a partir de 2005, sob a denominação de Instituto Lobo para o Desenvolvimento da Educação, da Ciência e da Tecnologia, uma instituição sem fins lucrativos, com sede no mesmo local, com coincidência nas atividades, com exceção de oferta da assessoria e da consultoria. A terceira atua nas áreas de consultoria de gestão, estudos de mercado, educação executiva, produção de conteúdo e metodologias de ensino; foi fundada pelo professor Ryon Braga em 1997 (CARVALHO, 2013, p. 766).
\end{abstract}

Luz (2011) alerta que a participação do empresariado nas políticas sociais, em particular nas políticas educacionais, ocorre sob várias perspectivas. Segundo a autora, as muitas empresas de consultoria criam estruturas de análise de dados sobre os índices da educação, financiam publicações de autores do meio educacional, criam e promovem instituições e sistemas educacionais que produzem materiais pedagógicos os 
quais são consumidos pelos professores e pelos investidores interessados em ampliar negócios e aumentar capital.

\section{CONSIDERAÇÕES}

A ênfase e as expectativas sobre o setor educacional na ordenação neoliberal criou desafios completamente novos e distintos para a formação de Pedagogos e, por consequência, para os rumos da Educação Básica no Brasil. Ao ser considerada apenas como mais um serviço prestado à comunidade e perdendo suas propriedades de direito, a Educação no Brasil tornou-se alvo de grandes corporações. Como já vimos, anteriormente, um dos setores afetados é o Ensino Superior e, consequentemente, a formação inicial de Pedagogos.

Assim, na análise dos materiais coletados, encontramos um dos fatores que promove a inserção de grandes conglomerados educacionais privados na formação desses profissionais: uma rede complexa de instituições, atores, organismos internacionais e setores públicos que criam mecanismos de controle e manutenção do sistema capitalista. As subjetividades construídas por esses atores parecem que não podem ser enfrentadas facilmente, nem individualmente, pois um fluxo de documentos de organizações internacionais enfatiza a necessidade de mudanças radicais, no ensino e na aprendizagem, tanto no que tange aos professores em formação quanto aos alunos das escolas espalhadas por todas as redes públicas nacionais.

Outro fator que podemos observar para a inserção de redes privadas na formação de Pedagogos são as políticas públicas educacionais. São políticas formuladas a partir da lógica neoliberal, com textos que possibilitam e suscitam inúmeras formas para a mercantilização da formação de Pedagogos no Brasil. Nessa lógica, pensada de forma intencional, as empresas privadas criam as mais variadas possibilidades para quem deseja trabalhar com Educação, quais sejam: oferecer facilidades, flexibilidade, superficialidade, preços acessiveis, atendimento às avaliações em larga escala, pouca rigidez, tanto teórica, quanto metodológica, entre outras. Essa oferta pode ser de cursos que formam os professores, na elaboração de 
materiais didáticos para o desenvolvimento das práticas pedagógicas, ou, ainda, um pacote completo de cursos de formação continuada, sites, exemplos de práticas pedagógicas definindo como e o que ensinarão os professores.

A formação de Pedagogos quando executada pelas redes privadas muda tanto a forma quanto o conteúdo educacional para atender às demandas neoliberais. O que se observa é a criação de novos nichos de mercado, ou seja, a Educação tal como ofertada e praticada, abre possibilidade de novos negócios quanto à produção de material didático, à assessoria das redes educacionais, à aquisição de novas tecnologias educacionais, etc.

A realidade apresentada nas análises deste trabalho demostra que grandes conglomerados educacionais dominam a formação de Pedagogos. As grandes empresas de educação no Brasil têm disseminado por meio de sua rede de empresas, cursos de formação inicial de Pedagogos. Os cursos são planejados a partir do mesmo Projeto Pedagógico e da mesma matriz curricular. Não há indícios de que a realidade local ou as especificidades de cada comunidade possam ser consideradas ou pensadas na oferta dos cursos destas empresas. Identificamos, nas instituições pesquisadas, elementos que guiam os cursos de formação de Pedagogos em uma perspectiva massificadora, no sentido de atender a grandes públicos, um modelo baseado em um mercado que lucra muito mais com a quantidade do que com a qualidade.

A "marketização" é outro elemento observado, pois as propagandas são formas de atrair clientes, criadas para a privatização velada da formação de Pedagogos, que ocorre por meio dos financiamentos estudantis patrocinados pelo governo federal. Os entrelaçamentos de diferentes atores também foram elementos que prevaleceram nas evidências dos dados coletados. As políticas, as reformas, as inovações são racionalizadas e utilizadas para (re)organizar o Estado e trazer as normas do privado para o público com agilidade e de forma eficaz. 
O Estado, nesse cenário, tem assumido um novo papel - talvez a mais importante diferença seja que o Estado não pode mais ser visto como o fator chave para entender as políticas educacionais e o único contexto da produção do texto das políticas. Há outras arenas de disputas compostas por diversos grupos de interesses. Essa é uma nova forma de governar, por meio da governança, ou de uma metagovernança traduzida em pluralidades e hierarquias que entrelaçadas e encontradas fortalecem os modos de coordenação prevalentes. Uma das suas características chave tem como fato de esses organismos participantes da governança não funcionarem contra o Estado, mas por meio dele. E, por isso, é que vemos, por vezes, as pequenas formas e grupos de resistência nem sempre terem argumentos para fortalecer seus discursos. O que ocorre realmente é que, no momento da criação dos textos das políticas, grupos enfrentam-se defendendo suas ideias, mas principalmente seus interesses de perpetuar-se no poder e na exploração do mercado.

E como continuar no poder? Operando dentro de um arcabouço de julgamento e avaliações na busca da definição de aperfeiçoamento e efetividade, determinados para nós e indicados por medidas de qualidade e produtividade. No caso da formação de Pedagogos, as medidas elaboradas pelo ENADE justificam a oferta de cursos de qualidade satisfatória. As constatações perseguem-nos, porém a tomada de atitude torna-se insipiente, pois grupos de interesses necessitam da validação do Estado regulador e performático para continuidade de seu projeto mercantilista. Tornamo-nos produtos mensuráveis e, para alcançar as metas, modificamos currículos e submetemos nossos alunos a práticas pedagógicas massificadoras e homogeneizadoras.

O presente estudo pôde identificar ainda o enfraquecimento do Estado e a permissão para a aprovação de políticas elaboradas e implementas sob uma perspectiva neoliberal possibilita a formação inicial de Pedagogos ser desenvolvida por instituições preocupadas com lucro e quantidade. 
Outra situação importante a destacar em nossos achados, diz respeito às decisões do governo em relação à Educação, pois elas definem a importância política atribuída a esse setor da ação governamental. Se, como observado nos nossos dados, as políticas enfraquecem ao invés de fortalecer o setor, o que podemos esperar como projeto de Educação para - Brasil? Um modelo de Educação que ainda apoia suas decisões considerando ideais neoliberais para a Educação, qual seja, a busca da qualidade total, no sentido de formar cidadãos eficientes, competitivos, líderes, produtivos, rentáveis, e transformar o Estado em uma máquina pública racionalizada.

Entendemos que este estudo torna-se importante, pois as instituições privadas que ofertam os cursos de Pedagogia, por meio de seus currículos e dos modos como são ofertados, criam subjetividades que moldam as práticas dos professores da Educação Básica, que, por sua vez, replicam as mesmas subjetividades às novas gerações. Nesse sentido, temos como pesquisadores compromissos éticos com o tema investigado. Nossa contribuição está relacionada às discussões sobre "[...] reflexividade ética e importância de se fazer uma auditoria ética do impacto e resultado das políticas e dos princípios e finalidades da pesquisa qualitativa crítica" (MAINARDES, 2013, p. 5).

Reconhecemos que, apesar dos dados apontarem para uma massificação de um único modelo para a formação de Pedagogos, há outros projetos educacionais espalhados pelo Brasil que buscam construir caminhos alternativos aos modelos gerencialistas neoliberais. São esses modelos que poderão gerar novos estudos contrapondo a realidade encontrada neste estudo.

Algumas limitações colocaram-se na trajetória deste estudo, dentre elas tamanho e a exigência de interdisciplinaridade, dada a natureza do objeto que é, nesse sentido, fenômeno econômico-financeiro, social, cultural, educacional e político. Assim, entendemos que outros estudos podem empreender esforços no sentido de investigar o fenômeno da privatização da formação inicial de Pedagogos utilizando outros 
instrumentos, outros dados e outras perceptivas teóricas que enriquecerão sobremaneira as discussões e a melhoria da Educação brasileira.

Firmes no compromisso ético, não podemos perder de vista o ideal de Educação, justiça e igualdade. Para tanto, acreditamos em uma formação de Pedagogos que irão atuar na formação das novas gerações, que promova autonomia, compromisso político do educador, o que implica a formação da consciência crítica. Daí,a importância do aprofundamento do domínio filosófico, sociológico, político e psicológico do processo educativo.

\section{REFERÊNCIAS}

ADORNO, T. W. Educação e emancipação. Rio de Janeiro: Paz e Terra, 1995.

ADRIÃO, T. et al. Uma modalidade peculiar de privatização da educação pública: a aquisição de "sistemas de ensino" por municípios paulistas".

Educação \& Sociedade, Campinas, v. 30, n. 108, p. 799-818, out. 2009.

BALL, S. J. Education PIc: private sector participation in public sector education. London: Routledge, 2007.

BALL, S. J. Vozes/Redes Políticas e um currículo neoliberal global. In: PEREIRA, M. Z. C. et al. Diferenças nas Políticas de Currículo. João Pessoa: UFPB, 2010.

BALL, S. J. A "nova" filantropia, o capitalismo social e as redes de políticas globais em educação. In: PERONI, V. M. V. Redefinições das fronteiras entre o público e o privado: implicações para a democratização da educação. Brasília: Liber Livro, 2013a.

BALL, S. J. Novos Estados, nova governança e nova política educacional. In: APPLE, M. W.; BALL, S. J.; GANDIN, L. A. Sociologia da Educação: Uma análise internacional. Porto Alegre: Penso, 2013b.

BALL, S. J. Educação global S.A.: novas redes políticas e o imaginário neoliberal. Tradução Janete Bridon. Ponta Grossa: UEPG, 2014.

BALL, S. J. Global Education INC: New Policy Networks and the neo-liberal imaginary. London: Routledge, 2012.

BARREYRO, G. B. Do Provão ao SINAES: o processo de construção de um novo modelo de avaliação da Educação Superior. Avaliação: Revista da Avaliação da Educação Superior da Rede de Avaliação Institucional da Educação Superior (RAIES), Sorocaba, v. 9, n. 2, p. 37-49, 2004. 
BAUMAN, Z. Globalização: As conseqüências humanas. Tradução Marcus Penchel. Rio de Janeiro: Jorge Zahar, 1999.

BRASIL. Censo da Educação Superior: 2014 - Resumo Técnico. Brasília: Instituto Nacional de Estudos e Pesquisas Educacionais Anísio Teixeira, 2016.

BRASIL. Lei NN 9.394, de 20 de dezembro de 1996. Diário Oficial [da] República Federativa do Brasil, Poder Legislativo, Brasília, DF, 23 dez. 1996. Seção 1, n. 248, p. 27833-27841.

BREJO, J. A. Estudo comparativo das políticas nacionais de formação de professores da educação infantil no Brasil e na Argentina (1990-2010). 2012. 282 f. Tese. (Doutorado em Educação) - Universidade Estadual de Campinas - UNICAMP, Campinas, SP, 2012.

BROWN, P.; LAUDER, H. Globalização Econômica, formação de habilidade e as consequências para o ensino superior. In: APPLE, M. W.; BALL, S. J.; GANDIN, L. A. Sociologia da Educação: Uma análise internacional. Porto Alegre: Penso, 2013.

CAMPOS, M. M.; FÜLLGRAF, J.; WIGGERS, V. A Qualidade da Educação Infantil Brasileira: alguns resultados de pesquisa. Cadernos de Pesquisa, São Paulo, v. 36, n. 127, p. 87-128, jan./abr. 2006.

CARVALHO, C. H. A. de. A mercantilização da educação superior brasileira e as estratégias de mercado das instituições lucrativas. Revista Brasileira de Educação, Rio de Janeiro, v. 18 n. 54, jul.-set. p.761-801, 2013.

CARVALHO, C. H. A. de. Análise da Política Pública de Expansão para a Educação Superior entre 1995 a 2010: Uma abordagem neoinstitucionalista histórica. Revista Brasileira de Educação, Rio de Janeiro, v. 20, p. 51-76, 2015.

CURY, C. R. J. Qualidade em Educação. Nuances: Estudos sobre Educação, Presidente Prudente, ano XVII, v. 17, n. 18, p. 15-31, jan./dez., 2010.

DALE, R. A promoção do mercado educacional e a polarização da educação. Revista Educação Sociedade e Culturas, Portugal, n. 2, p. 109139, 1994.

DALE, R. ROBERTSON S. Pesquisar a Educação em uma era globalizante. Educação \& Realidade, Porto Alegre, v. 36, n. 2, p. 347-363, maio/ago. 2011.

DOURADO, L. F. A qualidade da educação: conceitos e definições. Brasília: Instituto Nacional de Estudos e Pesquisas Educacionais Anísio Teixeira, 2007.

FRIGOTTO, G.; CIAVATTA, M. Educação Básica no Brasil na década de 1990: Subordinação ativa e consentida à lógica do mercado. Revista Educação e Sociedade, Campinas, v. 24, n. 82, p. 93-130, abr. 2003. 
GATTI, B. A.; BARRETTO, E. S. de S.; ANDRÉ, M. E. D. de A. Políticas docentes no Brasil: um estado da arte. Brasília: UNESCO, 2011.

HADDAD, S.; GRACIANO, M. Educação direito universal ou mercado em expansão. São Paulo em Perspectiva, São Paulo, v. 18, n. 3, p. 67-77, jul./set. 2004.

KLEES, S. J. D.; EDWARDS JR., B. Privatização da educação experiências dos Estados Unidos e outros países. Revista Brasileira de Educação, Rio de Janeiro, v. 20, n. 60 p.11-29, jan./mar. 2015.

MAINARDES, J. Informações sobre a abordagem do ciclo de políticas. Lista de obras de S. J. Ball e de pesquisas brasileiras que empregam suas ideias. 2013. Disponível em:

<http://www.pitangui.uepg.br/gppepe/download.php? file=Abordagem\%20 do\%20Ciclo\%20de\%20Politicas\%20_\%20Stephen\%20J.\%20Ball.pdf>. Acesso em: 4 jan. 2014.

MANCEBO, D.; VALE A. A. do; MARTINS T. B. Políticas de expansão da educação superior no Brasil 1995-2010. Revista Brasileira de Educação, Rio de Janeiro, v. 20 n. 60, p. 31-49, jan./mar. 2015.

MONTEIRO, C. A. CM Consultoria. Panorama de Fusões e Aquisições de IES (7). 13 Abril 2012. 2012. Disponível em:

<http://www.admustache.com.br/sites/cm2/blog/1 15-panorama-defus\%C3\%B5es-e-aquisi\%C3\%A7\%C3\%B5es-de-ies-7>. Acesso em: 12 nov. 2013.

OLIVEIRA, R. P. de. A transformação da educação em mercadoria no Brasil. Revista Educação e Sociedade, Campinas, v. 30, n. 108, p. 739-760, out. 2009.

OLIVEIRA, O. F. O Conselho Municipal de Educação no Brasil: práticas políticas e deliberações públicas em Nova Iguaçú. 2008. Tese. (Doutorado em Filosofia e Ciências Humanas) - Universidade do Estado do Rio de Janeiro, 2008.

PAIXÃO, A. G. da. O direito ao Ensino Superior e o capital: $O$ caso Faculdade Anhanguera de Anápolis. 2010. 95 f. Dissertação (Mestrado em Direito, Relações Internacionais e Desenvolvimento) - Pontifícia Universidade Católica de Goiás, Goiânia, 2010.

PERONI, V. M. V. A privatização do público implicações para a democratização da Educação. IN: PERONI, V. M. V. Redefinições das fronteiras entre o público e o privado: implicações para a democratização da Educação. Brasília: Liber Livro, 2013.

REGIONAL.com.br. Setor privado representa forte crescimento na última década. 2013. Disponível em: <http://www.oregional.com.br/2013/10/setorprivado-representa-forte-crescimento-na-ultima-decada_304849>. Acesso em: 12 nov. 2013. 
RIBEIRO, G. F. Afinal, o que a organização mundial do comércio tem a ver com a educação superior? Revista Brasileira de Política Internacional, Rio de Janeiro, n. 49, p. 137-156, 2006.

ROBERTSON, S.; DALE, R. Critical cultural political economy of the globalisation of education. Globalisation, Societies and Education, v. 13, n. 1, p.149-170, 2015.

SAMPAIO, H. Ensino Superior privado: inovação e reprodução no padrão de crescimento. Estudos. Revista da Associação Brasileira de Mantenedores de Ensino Superior (ABMES). Ano 27, n. 39, p.45- 58, dez. 2010.

SAMPAIO, H. Educação e Lucro. O setor privado de ensino superior no Brasil: continuidades e transformações. Revista Ensino Superior Unicamp, 4 de outubro de 2011 a.

SÃO PAULO. Mapa do Ensino Superior no Estado de São Paulo. Sindicato das Entidades Mantenedoras de Estabelecimentos de Ensino Superior no Estado de São Paulo - SEMESP, 2012.

SAVIANI, D. Da nova LDB ao FUNDB: por uma outra política educacional. Campinas, SP: Autores Associados, 2007.

SIQUEIRA, T. C. A. de. Ensino superior privado: notas sobre o trabalho dos docentes nas instituições particulares de ensino superior em Brasília. Revista de Ciências Sociais, Fortaleza, v. 40, n. 2, p. 61-72, 2009.

SGUISSARDI, V. Modelo de Expansão da Educação Superior no Brasil: Predomínio privado/mercantil e desafios para a regulação e a formação universitária. Revista Educação e Sociedade, Campinas, v. 29, n. 105, p. 9911022, set./dez. 2008.

VAILLANT, D. Atraer y retener buenos profesionales en la profesión docente: políticas en Lationoamérica. Revista Educación, n. 340, p. 117-140, 2006.

VERGER, A. Regionalización de la educación superior y globalización económica: El caso del proceso de Bologna. Universitat Autònoma de Barcelona 2011. Disponível em:

<http://www.academia.edu/6674875/Regionalizaci\%C3\%B3n_de_la_educaci \%C3\%B3n_superior_y_globalizaci\%C3\%B3n_econ\%C3\%B3mica_El_caso_del_pr oceso_de_Bologna?>. Acesso em: 29 fev. 2015.

Recebido em: 08 de agosto de 2018 Aprovado em: 03 de julho de 2019 